\title{
GAMBARAN UMUM HYGIENE SANITASI PEDAGANG MAKANAN JAJANAN DI PANTAI BERAWA DESA TIBUBENENG KECAMATAN KUTA UTARA KABUPATEN BADUNG TAHUN 2018
}

\author{
Adek Dwi Anggi Astiti ${ }^{1}$, I Wayan Suarta Asmara ${ }^{2}$
}

\begin{abstract}
Berawa Beach originated from Bali which is one of the beaches that are in demand by domestic tourists as well as foreign tourists as a tourist place located in the Badung area of North Kuta District. Increased tourist arrivals that occur require the availability of food snacks in Berawa beach area. The purpose of this research is to find out the General Description of Hygiene Sanitation of Food Traders in Berawa Beach Tibubeneng Village, North Kuta Sub-district, Badung Regency in 2018. The research type is descriptive observation with survey method on street vendors and observing sanitation facilities around street vendors which is at the location of Berawa Beach. From six of the street vendors in Berawa Beach, they get the result that is on the traders of cilok, chicken noodles, meatballs, and food and beverage traders are included in the less qualified category whereas the fried traders and maize traders are included in the unqualified category. From 16 questions on the examination of sanitation facilities around the street vendors in Berawa Beach get a total value of 5 which included in the category does not meet the requirements. The total results of all six peddlers there are four street vendors included in the unqualified category and two street vendors included in the less qualified category. For the merchants more to maintain food hygiene as well as for the coast manager is advised to better facilitate the state of Berawa.
\end{abstract}

Keywords: Hygiene, street hawkers and facilities

Penyakit diare merupakan masalah kesehatan masyarakat di Indonesia dapat dilihat dengan meningkatnya angka kesakitan diare dari tahun ke tahun. Sebanyak 6 juta anak meninggal setiap tahun karena diare, sebagian kematian tersebut terjadi di negara berkembang. Berdasarkan laporan WHO di tahun 2010 kematian karena diare di Indonesia sudah menurun tajam.
Begitu pula berdasarkan survey rumah tangga, kematian karena diare diperkirakan menurun. Walaupun angka kematian menurun, angka kesakitan karena diare tetap tinggi terutama di Negara berkembang ${ }^{1}$.

Makanan merupakan kebutuhan mendasar bagi hidup manusia. Makanan yang dikonsumsi beragam jenis dengan berbagai cara pengolahannya. Makanan-makanan 
tersebut sangat mungkin sekali menjadi penyebab terjadinya gangguan dalam tubuh kita sehingga kita jatuh sakit. Salah satu cara untuk memelihara kesehatan adalah dengan mengkonsumsi makanan yang aman, yaitu dengan memastikan bahwa makanan tersebut dalam keadaan bersih dan terhindar dari penyakit. Banyak sekali hal yang dapat menyebabkan suatu makanan menjadi tidak aman. Salah satu di antaranya dikarenakan terkontaminasi. Penyebab diare pada orang dewasa dan anak-anak umumnya adalah infeksi usus. Infeksi usus bisa terjadi ketika kita mengonsumsi makanan atau minuman yang kotor dan terkontaminasi. $^{2}$ Pantai Berawa merupakan salah satu pantai yang diminati oleh wisatawan domestik maupun wisatawan manca negara sebagai tempat wisata yang berada di wilayah Badung Kecamatan Kuta Utara. Peningkatan kunjungan wisatawan yang terjadi mengharuskan adanya ketersediaan makanan jajanan di kawasan pantai Berawa. Hygiene pada pedagang kaki lima di wilayah Pantai Berawa masih kurang, untuk melakukan penelitian ini yang bertujuan untuk mengetahui hygiene perorangan dari pedagang kaki lima dan mengamati fasilitas sanitasi di Pantai Berawa. Terdapat 6 pedagang kaki lima yang berjualan di Pantai Berawa. Pengamatan dilihat dari hygiene perorangan dari pedagang kaki lima dan dilihat dari fasilitas sanitasi di sekitar pedagang kaki lima yang berada di Pantai Berawa. Disini penulis akan melakukan observasi dengan menggunakan lembar observasi untuk mengetahui keadaan hygiene perorangan pedagang kaki lima dan fasilitas sanitasi dengan wawancara kepada pedagang kaki lima untuk mengetahui keadaan hygiene perorangan dan fasilitas sanitasi di Pantai Berawa.

Tujuan penelitian ini yaitu untuk mengetahui gambaran umum hygiene sanitasi pedagang makanan jajanan di pantai Berawa Desa Tibubeneng Kecamatan Kuta Utara Kabupaten Badung Tahun 2018 yang meliputi hygiene perorangan dari pedagang kaki lima dan kondisi fasilitas sanitasi. Manfaat penelitian ini yaitu dapat memberikan informasi serta gambaran tentang keadaan hygiene dari penyajian 
makanan dan minuman pada pedagang kaki lima di Pantai Berawa, diharapkan pula hasil dari penelitian ini dapat menjadi masukan bagi pedagang makanan jajanan dalam hal hygiene sanitasi pedagang. Serta manfaat teoritis yaitu dapat memberikan sumbangan ilmu pengetahuan khususnya dalam bidang hygiene sanitasi pedagang makanan jajanan. Untuk dapat dijadikan sebagai dasar atau tambahan refrensi dalam hygiene sanitasi pedagang.

\section{METODE}

Jenis penelitian yang dilakukan adalah deskriptif yang bersifat observasi dengan metode survey pada hygiene perorangan dari pedagang kaki lima dan fasilitas sanitasi di Pantai Berawa.

Data Primer dalam penelitian ini yaitu dilakukan dengan observasi dengan menggunakan lembar observasi untuk mengetahui keadaan hygiene perorangan dari pedagang kaki lima dan wawancara kepada pedagang untuk mengetahui keadaan hygiene dan keadaan dari tempat fasilitas sanitasi di Pantai Berawa. Data sekunder yang digunakan dalam penelitian yaitu Data yang berasal dari pedagang kaki lima seperti biodata dari pedagang di

\section{HASIL DAN PEMBAHASAN}

Pantai Berawa merupakan salah satu pantai yang diminati oleh wisatawan domestik maupun wisatawan manca negara sebagai tempat wisata yang berada di wilayah Badung Kecamatan Kuta Utara. Pantai Berawa berada di satu jalur dengan Pantai Petitenget. Gelombang ombak yang dimiliki oleh pantai ini sangat besar sehingga mampu menarik perhatian dari para peselancar. Lokasi dari tempat wisata ini bisa ditempuh dengan jangka waktu sekitar 20 menit dari Kuta dengan menggunakan mobil atau motor. Peningkatan kunjungan wisatawan yang terjadi mengharuskan adanya ketersediaan makanan jajanan di kawasan pantai Berawa. 
Hygiene perorangan pada pedagang kaki lima di Pantai Berawa Desa Tibubeneng Kecamatan Kuta Utara Kabupaten Badung Tahun 2018.

\begin{tabular}{llcc}
\hline No & $\begin{array}{l}\text { Nama Pedagang } \\
\text { Kaki Lima }\end{array}$ & Jumlah Nilai & Kategori Hasil \\
\hline 1 & Pedagang Cilok & 5 & Kurang memenuhi syarat \\
2 & Pedagang Mie Ayam & 4 & Kurang memenuhi syarat \\
3 & Pedagang Bakso & 4 & Kurang memenuhi syarat \\
4 & Pedagang Gorengan & 3 & Tidak memenuhi syarat \\
5 & Pedagang Jagung & 3 & Tidak memenuhi syarat \\
6 & Pedagang Makanan & 5 & Kurang memenuhi syarat \\
& dan Minumah & & \\
\hline
\end{tabular}

Hasil pemeriksaan hygiene pedagang gorengan dan pedagang perorangan dari pedagang kaki lima di Pantai Berawa dengan jumlah rata - rata skor yaitu pedagang cilok mendapatkan skor 5 , pedagang mie ayam mendapatkan skor 4 , pedagang bakso mendapatkan skor 4, pedagang gorengan mendapatkan skor 3, pedagang jagung mendapatkan skor 3 , pedagang makanan dan minuman mendapatkan skor 5. Dari enam pedagang kaki lima di Pantai Berawa tersebut mendapatkan hasil yaitu pada pedagang cilok, mie ayam, bakso, dan pedagang makanan dan minuman termasuk dalam kategori kurang memenuhi syarat dengan presentase $74,8 \%$ (yang dibulatkan menjadi $75 \%$ ) sedangkan pada jagung termasuk dalam kategori tidak memenuhi syarat dengan presentase $25 \%$. Hasil pemeriksaan hygiene perorangan dari pedagang kaki lima di Pantai Berawa dari keenam pedagang kaki lima yang diperiksa mendapatkan hasil dengan katagori tidak memenuhi syarat. Menurut Keputusan Menteri Kesehatan Republik Indonesia Nomor 942/Menkes/SK/VII/2003 tentang Pedoman Persyaratan Hygiene Sanitasi Makanan Jajanan ${ }^{3}$. Berdasarkan hasil penelitian dari kejadian penyakit yang ditularkan melalui makanan di Indonesia cukup besar terlihat dari masih tingginya penyakit infeksi seperti tifus, kolera, 
desentri, dan tbc. ${ }^{4}$ Sebaiknya pekerja yang menangani makanan harus mengikuti prosedur sanitasi yang memadai untuk mencegah kontaminasi pada makanan yang ditangani.

Tabel 4

Kondisi fasilitas sanitasi sekitar pedagang kaki lima di Pantai Berawa Desa

Tibubeneng Kecamatan Kuta Utara Kabupaten Badung Tahun 2018.

\begin{tabular}{llc}
\hline No & Item Penelitian & Jumlah Nilai \\
\hline 1 & Fasilitas cuci tangan pakai sabun & 0 \\
2 & Lokasi pedagang jauh dari kamar & 1 \\
& mandi/wc (minimal 10 M) & \\
3 & Lokasi pedagang jauh dari tempat & 1 \\
& $\begin{array}{l}\text { penampungan sampah } \\
4\end{array}$ & Kamar mandi /wc/ jamban \\
5 & Tempat sampah & 3 \\
\hline & Total Jumlah Nilai & 0 \\
\hline
\end{tabular}

Hasil pemeriksaan kondisi fasilitas sanitasi sekitar pedagang kaki lima di Pantai Berawa dibandingkan berdasarkan Keputusan Menteri Kesehatan Republik Indonesia Nomor 942/Menkes/SK/VII/2003 tentang Pedoman Persyaratan Hygiene Sanitasi Makanan Jajanan yang mencangkup tentang persyaratan kondisi fasilitas sanitasi. Kondisi fasilitas sanitasi ada 16 pertanyaan pada pemeriksaan kondisi fasilitas sanitasi sekitar pedagang kaki lima di Pantai Berawa, pada fasilitas sanitasi sekitar pedagang kaki lima di Pantai Berawa dari 16 pertanyaan pada pemeriksaan fasilitas sanitasi sekitar pedagang kaki lima di Pantai Berawa tersebut mendapatkan total nilai yaitu 5 yang termasuk dalam kategori tidak memenuhi syarat. Dari hasil pengamatan sekitar kurang lebih ada 50 pengunjung yang datang ke Pantai Berawa. Berdasarkan hasil penelitian dari Aidil Rahman 
(2016), pengunjung mengatakan bahwa kurangnya fasilitas kamar mandi / wc tidak bersih yang berada di sekitaran objek wisata Pantai Pasir Jambak, pengunjung mengatakan bahwa kurangnya fasilitas yang disediakan di objek wisata Pantai Pasir Jambak. Hasil pengamatan kondisi fasilitas sanitasi sekitar pedagang kaki lima di Pantai Berawa yang termasuk katagori tidak memenuhi syarat. Karena pada kondisi fasilitas di Pantai Berawa tersebut tidak tersedia tempat cuci tangan dan cuci peralatan pedagang kaki lima dengan air yang mengalir, tidak tersedianya tempat cuci tangan bagi pengunjung di Pantai Berawa dikarenakan sulit untuk mendapatkan air karena di Pantai Berawa kamar mandi / wc yang di sediakan tidak layak untuk digunakan karena tidak bersih dan kotor.

Dampak yang ditimbulkan dari tidak terpenuhinya persyaratan kondisi fasilitas tersebut dapat mempengaruhi kualitas kebersihan lingkungan sekitar dan menjadi kurangnya kebersihan terhadap makanan dan minuman yang di jual pada pedagang kaki lima. Bagi pihak pengelola Pantai Berawa diharapkan untuk selalu menjaga kebersihan lingkungan agar menyiapkan tempat untuk membuang sampah dan pemilahan sampah organic maupun anorganik di Pantai Berawa. Dan diharapkan juga untuk menyediakan kamar mandi / wc yang bersih dan memfasilitasi untuk kenyamanan pengunjung.

\section{SIMPULAN DAN SARAN}

\section{Simpulan}

Berdasarkan hasil penelitian yang telah dilakukan, maka dapat disimpulkan bahwa: Hygiene perorangan dari pedagang kaki lima di Pantai Berawa Desa Tibubeneng Kecamatan Kuta Utara Kabupaten Badung mendapatkan hasil dari keenam pedagang kaki lima ada 4 pedagang kaki lima termasuk dalam kategori kurang memenuhi syarat dengan presentase $74,8 \%$ (yang dibulatkan menjadi 75\%) dan 2 pedagang kaki lima yang termasuk dalam katagori tidak memenuhi syarat dengan presentase $25 \%$ sesuai dengan Kepmenkes RI Nomor 942/Menkes/SK/VII/2003. Kondisi fasilitas sanitasi sekitar pedagang kaki lima di Pantai Berawa dari 16 pertanyaan pada pemeriksaan 
fasilitas sanitasi di Pantai Berawa tersebut mendapatkan total nilai yaitu 5 yang termasuk dalam kategori tidak memenuhi syarat sesuai dengan Kepmenkes RI Nomor 942/Menkes/SK/VII/2003.

\section{Saran}

Saran yang dapat peneliti
sampaikan yaitu bagi pihak pedagang disarankan untuk menjaga kebersihannya dalam menyajikan makanan agar terhindar dari adanya bakteri. Kemudian biasakan sebelum menyiapkan makanan tersebut harus mencuci tangan dan peralatan dengan air mengalir agar terhindar dari kontaminasi terhadap bakteri. Kepada pihak pengelola Pantai Berawa disarankan untuk selalu menjaga kebersihan lingkungan dengan menyiapkan tempat untuk membuang sampah dan pemilahan sampah organik maupun anorganik di Pantai Berawa. Dan diharapkan juga untuk menyediakan kamar mandi / wc yang bersih dan memfasilitasi untuk kenyamanan pengunjung.

\section{DAFTAR PUSTAKA}

1. Triwulan. Situasi DIARE di
Indonesia. Jakarta : Salemba

Medika. (2011).

2. Agustina, T. Pentingnya

Hygiene Penjamah Makanan.

Semarang : s.n. (2005).

3. Depkes RI. Kepmenkes

Nomor

942/Menkes/SK/VII/2003

Tentang Pedoman Persyaratan

Hygiene Sanitasi Makanan

Jajanan. diakses 18 Maret

2018). (2003).

4. Wahid Iqbal Mubarak, N. C. Ilmu Kesehatan Masyarakat Teori dan Aplikasi. Jakarta : Salemba Medika. (2009). 